\title{
Maximizing the Overall Satisfaction Degree of all Participants in the Market Using Real Code-based Genetic Algorithm by Optimally Locating and Sizing the Thyristor-Controlled Series Capacitor
}

\author{
Seyed M. H Nabavi ${ }^{\dagger}$, Somayeh Hajforoosh*, Sajad Hajforoosh*, \\ Ali Karimi* and Kamran Khafafi*
}

\begin{abstract}
The present paper presents a genetic algorithm (GA) to maximize social welfare and perform congestion management by optimally placing and sizing one Thyristor-Controlled Series Capacitor (TCSC) device in a double-sided auction market. Simulation results, with line flow constraints before and after the compensation, are compared through the Sequential Quadratic Programming SQP method, and are used to analyze the effect of TCSC on the congestion levels of modified IEEE 14-bus and 30-bus test systems. Quadratic, smooth and nonsmooth (with sine components due to valve point loading effect) generator cost curves, and quadratic smooth consumer benefit functions are considered. The main aims of the present study are the inclusion of customer benefit in the social welfare maximization and congestion management objective function, the consideration of nonsmooth generator characteristics, and the optimal locating and sizing of the TCSC using real code-based GA to guarantee fast convergence to the best solution.
\end{abstract}

Keywords: Congestion management, Double-sided auction market, Real code-based GA, Rescheduling, Social welfare maximization, TCSC.

\section{Introduction}

Competition in a deregulated power system will set a fair market structure and motivate all participants to maximize their own individual profit. This will allow the market to behave in a manner that maximizes profit for all participants. In addition to deregulation challenges, electrical loads are rapidly growing and some transmission lines are reaching their thermal limits. Congestion can be relieved by building new transmission lines; however, this is an expensive solution that requires years for approval and construction. An accepted solution for the Independent System Operator (ISO) is to perform congestion management, which is the process of ensuring that a transmission system does not violate its operating limits. If congestion management is not properly implemented, then a barrier to electricity trading by preventing new contracts is imposed, which leads to additional outages, increased electricity prices in some regions, and threatened system security and reliability [1].

In conventional literature, transmission improvement methods are applied to achieve a minimum generation cost that is subject to system security constraints. In contrast, social welfare maximization and congestion management

$\dagger$ Corresponding Author: Department of Electrical and Electronic Engineering, Tabriz Branch, Islamic Azad University, Tabriz, Iran. (H nabavi@ee.iust.ac.ir)

* Department of Electrical and Electronic Engineering, Tabriz Branch, Islamic Azad University, Tabriz, Iran.

Received: September 14, 2010; Accepted: March 3, 2011 are the objectives of most papers in deregulated power systems. Numerous methods based on market model [1], particle swarm optimization (for generation rescheduling and/or load shedding) [2], genetic algorithm (GA) [3], and sensitivity analysis using transmission line susceptances [4] have been reported for social welfare maximization and congestion management. Distributed generators that locate social welfare maximization are presented in [5]. Maximization of social welfare is represented as a marginal benefit versus demand function in [6]. Reference [7] discovered a method for increasing social welfare under congestion probability in a transmission network. Similarly, several studies have been published in competitive electricity markets based on transmission expansion. Optimal transmission network expansion in centralized and decentralized power markets is offered in [8], and a new market-based transmission expansion planning is accessible in [9].

Recent solutions for managing power flow in transmission lines are based on flexible AC transmission systems (FACTS) [10]. Different approaches based on sensitivity method have been proposed for optimally locating FACTS devices in both vertically integrated and unbundled power systems [11-13]. Congestion management by interline power flow controller (IPFC) and unified power flow controller (UPFC) are performed in [12-14]. The application of a series of FACTS for congestion management in deregulated electricity markets is discussed in $[15]$. 
These references simplify the optimization problem by assuming the given sizes of FACTS devices and/or using second order objective benefit functions without considering the sine components due to valve point loading effects.

The present paper proposes a real code-based GA for alleviating congestion and maximizing social benefit in a double-sided auction market by optimally locating and sizing one Thyristor-Controlled Series Capacitor (TCSC) unit. Simulations are performed to investigate the effect of TCSC on congestion levels of the modified IEEE 14-bus and 30-bus test systems with quadratic smooth and quadratic nonsmooth (with sine components due to valve point loading effect) generator cost curves and quadratic smooth benefit functions for loads. The proposed method shows the benefits of TCSC in a deregulated power market, and demonstrates how they may be utilized by ISO to prevent congestion and improve total social welfare.

\section{Mathematical Model of TCSC}

In the present paper, the Newton-Raphson (N-R) power flow formulation is used. TCSC is represented using the Power Injection Model [15], which will allow the easy integration of TCSC devices into existing power system software tools and retain the symmetrical structure of the admittance matrix. The change in line flow due to series capacitance is represented as a line without series capacitance with powers injected at the receiving and sending ends (Fig. 1).

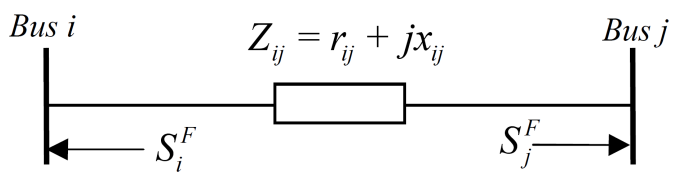

Fig. 1. Power injection model of transmission line with TCSC.

The real and reactive power injections at buses $i$ and $j$ with a TCSC connected in line $i j$ can be expressed as [15]:

$$
\begin{aligned}
P_{i}^{F} & =V_{i}^{2} \Delta G_{i j}-V_{i} V_{j}\left[\Delta G_{i j} \cos \delta_{i j}+\Delta B_{i j} \sin \delta_{i j}\right] \\
P_{j}^{F} & =V_{j}^{2} \Delta G_{i j}-V_{i} V_{j}\left[\Delta G_{i j} \cos \delta_{i j}-\Delta B_{i j} \sin \delta_{i j}\right] \\
Q_{i}^{F} & =-V_{i}^{2} \Delta B_{i j}-V_{i} V_{j}\left[\Delta G_{i j} \sin \delta_{i j}-\Delta B_{i j} \cos \delta_{i j}\right] \\
Q_{i}^{F} & =-V_{j}^{2} \Delta B_{i j}+V_{i} V_{j}\left[\Delta G_{i j} \sin \delta_{i j}+\Delta B_{i j} \cos \delta_{i j}\right]
\end{aligned}
$$

where $\Delta G_{i j}=x_{c} r_{i j}\left(x_{c}-2 x_{i j}\right) /\left(r_{i j}^{2}+x_{i j}^{2}\right)\left(r_{i j}^{2}+\left(x_{i j}-x_{c}\right)^{2}\right)$ and $\Delta B_{i j}=-x_{c}\left(r_{i j}^{2}-x_{i j}^{2}+x_{c} x_{i j}\right) /\left(r_{i j}^{2}+x_{i j}^{2}\right)\left(r_{i j}^{2}+\left(x_{i j}-x_{c}\right)^{2}\right)$.

Eqs. 1-4 are added to the Jacobian matrix in N-R load flow formulations.

\section{Problem Formulation in the Double Auction Power Pool}

In the double-sided auction market model, both DisCos and GenCos participate in the market and offer their bidquantity packages to the market operator. Supply-side participants submit an offer (the quantity and associate price) for selling energy to the pool, whereas demand-side participants submit an offer for buying from the pool. By classifying and sorting supplier bids from minimum to maximum, and demand bids in a decreasing order, the system price is achieved. According to Fig. 2, the crossing point of these curves obtains the system price and the amount of energy cleared for trading. Therefore, the ISO looks for ways to maximize social welfare [16].

In the present paper, there are $\mathrm{N}$ supplier bids with bid price (BPS) and M customer's bids with bid price (BPB). BPS and BPB are assumed to represent the generator and customer's true marginal cost, respectively, as follows:

$$
C_{i}=f\left(P_{i}\right), B_{j}=g\left(P D_{j}\right) \quad \forall i \in N \text { and } \forall j \in M
$$

where $C_{i}$ is the generation cost function for generator $i$, $P_{i}$ is the generation amount, $B_{j}$ is the benefit function of customer $j$, and $P D_{j}$ is the demand of customer.

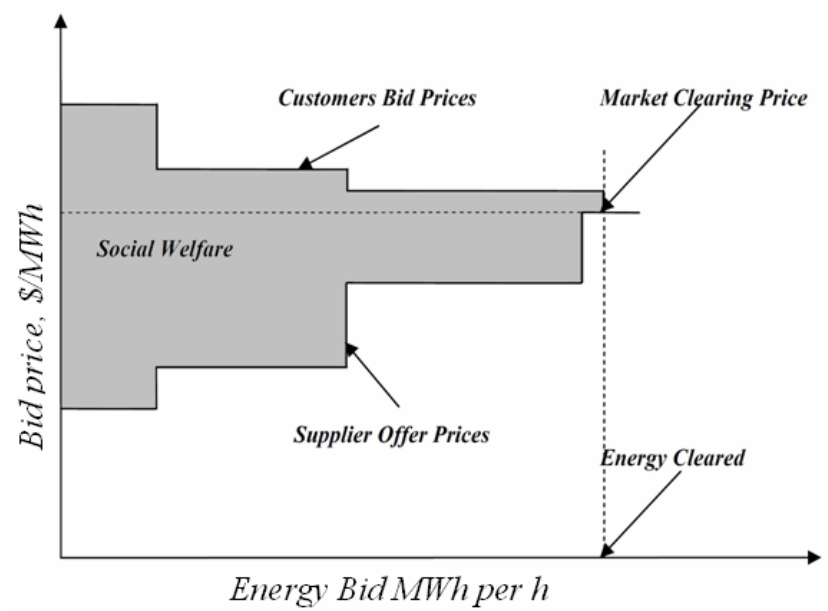

Fig. 2. Market settlement in double auction power pools [16].

The definition of social welfare function is defined as the total customer benefit and net of total cost to generator [16], which is represented by the following equation:

Social welfare function

$$
\begin{aligned}
& =\sum_{j=1}^{M} P D_{j} \cdot B P B_{j}-\sum_{i=1}^{N} P_{i} \cdot B P S_{i} \\
& =\sum_{j=1}^{M} B_{j}-\sum_{i=1}^{N} C_{i}=\sum_{j=1}^{M} g_{j}\left(P D_{j}\right)-\sum_{i=1}^{N} f_{i}\left(P_{i}\right)
\end{aligned}
$$


The first component of Eq. (6) presents the benefit functions of customers that are expressed by quadratic functions. Inclusion in this part of the objective function of the OPF problem will guarantee that locational marginal prices (LMPs) charged at demand buses are less than or equal to the benefit of customers, which is earned by selling that power to retail customers. In case of system congestion, the OPF will give a signal to reduce demand by a particular amount at those buses for which marginal benefit is less than marginal price, which ultimately leads to a reduction in system congestion [17].

The second component presents the cost functions of generators considering their nonsmooth behavior. To introduce a more accurate modeling, the valve loading effects is incorporated with the conventional quadratic smooth generator cost curves. The valve point loading effect in gradient-based algorithms introduces non-convex and non-differentiable regions, and complicates the optimization problem [18].

Therefore, the objective of the market operator is to maximize social welfare, including load flow equality and operational inequality constraints, which can be expressed as follows:

$$
\operatorname{Max}\left(\begin{array}{c}
\sum_{j=1}^{N_{D}}\left(a_{d j}+b_{d j} P_{D j}+c_{d j} P_{D j}^{2}\right) \\
-\left\{\begin{array}{c}
\sum_{i=1}^{N_{G}}\left(a_{g i}+b_{g i} P_{G i}+c_{g i} P_{G i}^{2}\right) \\
+\left|e_{g i} \times \operatorname{Sin}\left(f_{g i} \times\left(P_{G i}-P_{\operatorname{mini}}\right)\right)\right|
\end{array}\right\}
\end{array}\right)
$$

where $P_{D j}$ and $P_{G i}$ are dispatched loads and generations at nodes $j$ and $i$, respectively; $N_{D}$ and $N_{G}$ are the number of loads and generators, respectively; and " $a_{d j}, b_{d j}, c_{d j}$ " and " $a_{g i}, b_{g i}, c_{g i}, e_{g i}, f_{g i}$ " are the benefit function coefficients in customers and cost coefficients in generators, respectively. The objective function (Eq. (7)) is subjected to the following constraints:

(1) Power injection: the net injections of real and reactive power at each bus are set to zero.

(2) Generation limits: the limits on the maximum and minimum active power $\left(P_{G}\right)$ and reactive $\left(Q_{G}\right)$ power generation of the generators are included as

$$
P_{G i}^{\min } \leq P_{G i} \leq P_{G i}^{\max }, Q_{G i}^{\min } \leq Q_{G i} \leq Q_{G i}^{\max }, i=1, \ldots, N_{G},
$$

where $P_{G i}$ and $Q_{G i}$ are the active and reactive power generation vectors for bus $G_{i}$, respectively.

(3) Demand limits: the maximum and minimum limits of consumers active power $\left(P_{D}\right)$ and reactive power $\left(Q_{D}\right)$ demands are considered as

$$
P_{D i}^{\min } \leq P_{D i} \leq P_{D i}^{\max }, Q_{D i}^{\min } \leq Q_{D i} \leq Q_{D i}^{\max }, i=1, \ldots, N_{D},
$$

where $P_{D i}$ and $Q_{D i}$ are the active and reactive power demand vectors for bus $D_{i}$, respectively.

(4) Transmission limits: the line MVA limit is included as

$$
\begin{gathered}
\left|S_{l}(\theta, V)\right|^{2} \leq\left(S_{l}^{\max }\right)^{2} \\
S_{l}(\theta, V)=\operatorname{Max}\left(S_{i j}, S_{j i}\right) \\
S_{i j}(\theta, V)=V_{i}^{*}\left(V_{i}-V_{j}\right) y_{i j}+V_{i}^{*} V_{i} y_{i_{0}}
\end{gathered}
$$

where $y_{i_{0}}$ is the line-charging admittance and $y_{i j}$ is the admittance of line $i j$. Eq. (10) ensures that no congestion occurs in lines in the procedure of double action market clearing.

(5) Voltage limits: the voltage limit at each bus is expressed as

$$
V_{i}^{\min } \leq V_{i} \leq V_{i}^{\max }
$$

(6) Compensation limit: the maximum and minimum values of equivalent TCSC reactance $\left(x_{c}\right)$ are included as

$$
x_{c}^{\min } \leq x_{c} \leq x_{c}^{\max } .
$$

\section{Development of the Proposed Real Code-based GA}

The optimization problem consists of solving Eqs. (7)-(14). The incorporation of one TCSC device is a complex, large-scale, nonlinear programming dilemma that cannot be easily solved by conventional approaches. In the present paper, real code-based GA is used as a tool to capture the best solution.

GA is a global search technique based on the mechanisms of natural selection and genetics capable of searching several possible solutions simultaneously [19]. GA has been applied to many problems, including stability studies [20], load frequency control [21], reactive power compensation [22], V/Q/THD control [23], unit commitment [24], economic dispatch [25], optimal power flow [26], generation expansion planning [27], optimal location of FACTS devices [10], optimized system topology [28], loss minimization [29], distributed generator placement [30], and reliability assessment [31].

\subsection{Initial Population and Structure of Chromosomes}

A random number generator is used to select initial population chromosomes within the range of control variables. The selected chromosome structure contains generation and demand levels, as well as TCSC location and compensation level (Fig. 3). Real codes are used to 
achieve higher accuracy compared with binary coding.

\begin{tabular}{l|l|l|l|l|l|l|l|l|l}
\hline$P_{G_{1}}$ & $P_{G_{2}}$ & $\ldots$ & $P_{G_{N}}$ & $P_{D_{1}}$ & $P_{D_{2}}$ & $\ldots$ & $P_{D_{X D}}$ & $T C S C_{\text {Size }}$ & $T_{C S C_{\text {Location }}}$ \\
\hline
\end{tabular}

Fig. 3. Chromosome structure for the GA.

\subsection{Proposed Fitness Function}

GA procedure involves the evaluation of objective (fitness) functions to measure the quality of solutions. A solution with better quality (e.g., higher fitness value) will be included in the new population, whereas low quality solutions are discarded. In the present paper, exponential penalty functions for each generated chromosome are calculated for lines that have power overflows and/or reach voltage, generation, and load limits based on respective penalty functions as follows:

$$
F_{\text {fitness }}=F_{\text {line flow }} \cdot F_{\text {busvoltage }} \cdot F_{\text {generation }} \cdot F_{\text {load }}
$$

where $F_{\text {line flow }}=\prod_{j=1}^{\mathrm{N}_{\mathrm{L}}} F_{L}, \quad F_{\text {bus voltage }}=\prod_{j=1}^{\mathrm{N}_{B}} F_{V}, F_{\text {generation }}=\prod_{j=1}^{N_{G}} F_{G}$, and $F_{\text {load }}=\prod_{j=1}^{N_{D}} F_{D}$.

$N_{L}, N_{G}, N_{D}$, and $N_{B}$ are the number of branches, generators, loads, and buses in the power system, respectively, and $F_{\text {fitness }}$ is the fitness function value for each chromosome. The proposed penalty functions are

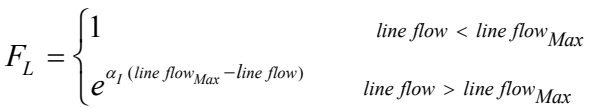

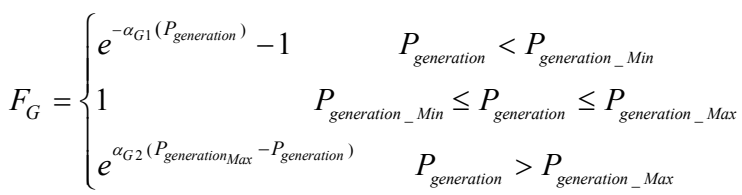

$$
\begin{aligned}
& F_{V}=\left\{\begin{array}{lc}
e^{-\alpha_{V 1}\left(V_{B u s}\right)}-1 & V_{B u s}<V_{\text {Min }} \\
1 & V_{\text {Min }} \leq V_{\text {Bus }} \leq V_{\text {Max }} \\
e^{-\alpha_{V 2}\left(V_{\text {Max }}-V_{\text {Bus }}\right)} & V_{B u s}>V_{\text {Max }}
\end{array}\right.
\end{aligned}
$$

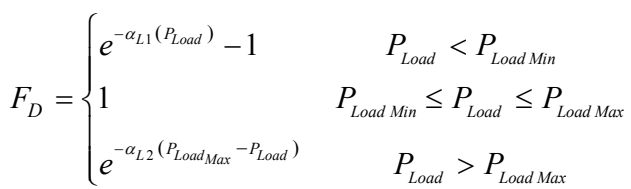

where $\alpha_{I}, \alpha_{G 1}, \alpha_{G 2}, \alpha_{L 1}, \alpha_{L 2}, \alpha_{V 1}$ and $\alpha_{V 2}$ are the coefficients used to adjust the slope of penalty functions (Fig. 4).

\subsection{Genetic Operators}

The selected GA operators are shown in Table 1. The probabilities of crossover and mutation are 0.9 and 0.1 , respectively.
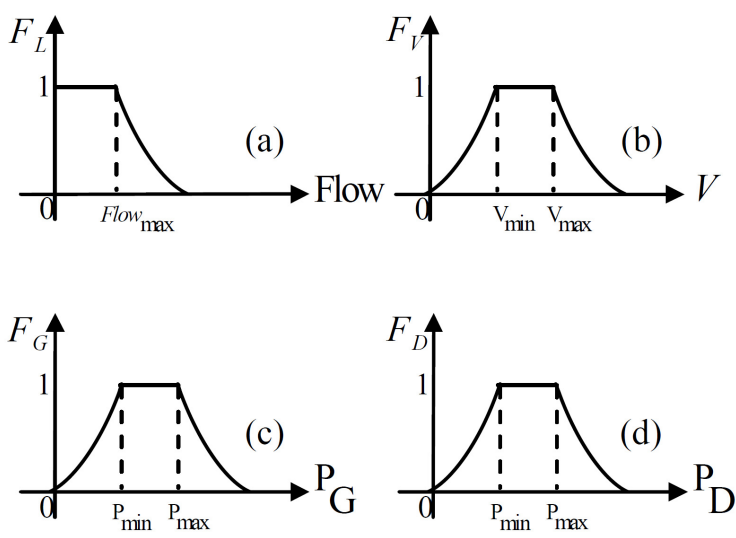

Fig. 4. Proposed penalty functions used to compute fitness (Eq. 13);
(a) $F_{\text {line flow Limit }}$,
(b) $F_{\text {busvoltage Limit }}$,

\section{Solution Methodology}

The problem defined by Eqs. (7)-(14) is solved using the proposed GA of Fig. 5. The main steps are as follows:

Step 1: Input power system parameters (e.g., system topology, line and load specifications, generation limits, line flow limits, and cost coefficient parameters).

Step 2: Assume a suitable population size $\left(N_{\text {ch_max }}\right)$ and a maximum number of generations $\left(N_{\text {it max }}\right)$. Set initial counters and parameter values (e.g., $N_{c h}=N_{i t}=1$ ). Generate random chromosomes by real coding.

Step 3 (Fitness Process):

Step 3A: Run power flow for each set of chromosomes and determine voltage magnitudes and phase angles at all buses. Calculate power flow in each transmission line of the system.

Step 3B: Compute proposed penalty functions (Fig. 4) using outputs of the applied power flow.

Step 3C: Compute fitness functions (Eq. (15)) for chromosome $N_{c h}$. Set $N_{c h}=N_{c h}+1$.

Step 3C: If $N_{c h} \leq N_{c h_{-} \max }$, go to Step 3A.

Step 4 (Reproduction Process):

Step 4A: Define total fitness as the product of all fitness values for all chromosomes.

Step 4B: Run a tournament for selection process. Select a new combination of chromosomes.

Step 5 (Crossover Process):

Step 5A: Select a random number $\left(\mathrm{R}_{1}\right)$ for mating two parent chromosomes.

Step $5 B$ : If $\mathrm{R}_{1}$ is less than the crossover values, then combine the two parents, generate two offspring, and go to Step 5D.

Step 5C: Otherwise, transfer the chromosome with no crossover. 


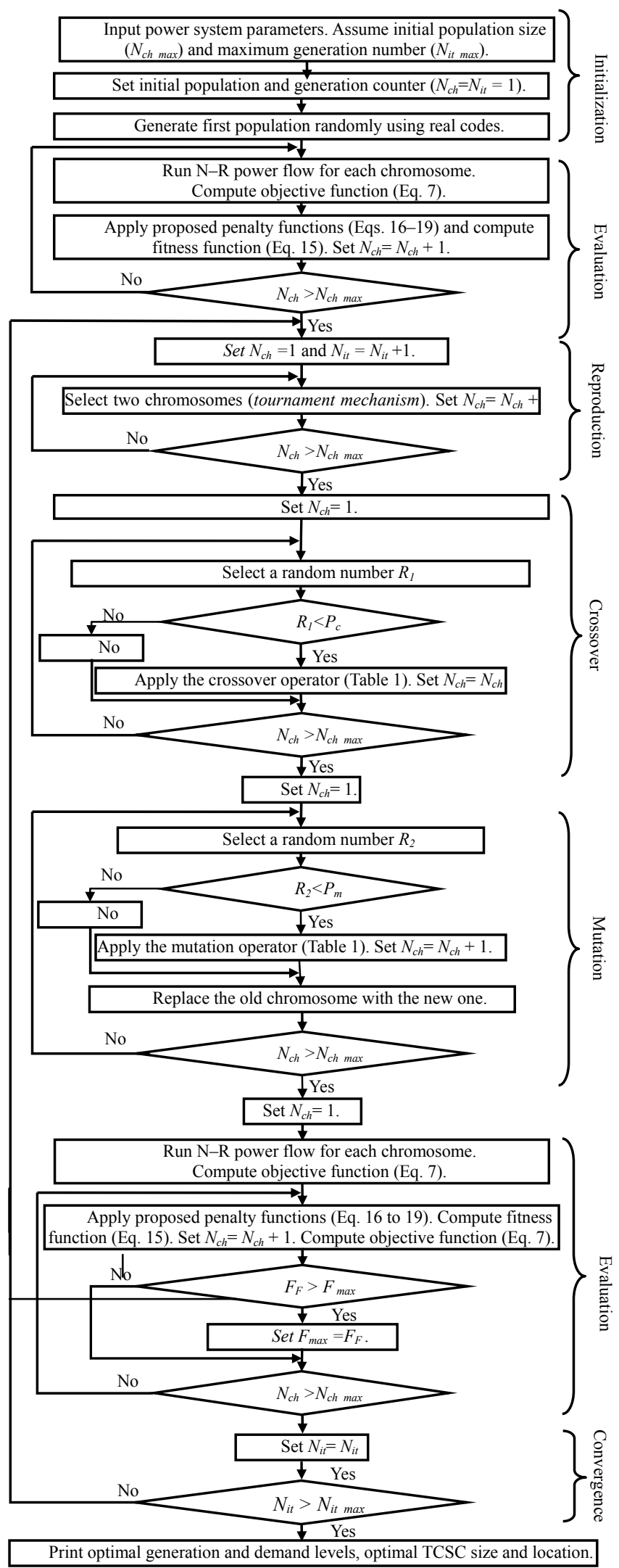

Fig. 5. Proposed Real Code-based GA algorithm for social welfare maximization by optimally locating and sizing one TCSC device.
Step 5D: Repeat steps 5A-D for all chromosomes. Step 6 (Mutation Process):

Step 6A: Select a random number $\left(\mathrm{R}_{2}\right)$ for the mutation of one chromosome.

Step 6B: If $\mathrm{R}_{2}$ is less than the values of mutation, then apply the mutation process and go to Step 6D.

Step 6C: Otherwise, transfer the chromosome with no mutation.

Step 6D: Repeat Steps 6A-C for all chromosomes.

Step 7A (Updating Populations): Replace the old population with the improved population generated by Steps 2-6.

Table 1. The selected genetic operators for the proposed algorithm

\begin{tabular}{|c|c|}
\hline GA Operators & Method \\
\hline Reproduction & Tournament selection \\
\hline $\begin{array}{l}\text { Heuristic } \\
\text { Crossover }\end{array}$ & $\begin{array}{l}p_{\text {new }}=\beta\left(p_{m n}-p_{d n}\right)+p_{m n} \\
\beta \text { is a random number on interval }(0,1) \text {, and } p_{m n} \text { and } \\
p_{d n} \text { are the } \mathrm{n}^{\text {th }} \text { variables in the parent chromosomes. } \\
\text { Crossover probability is selected to be } 0.9 \text {. }\end{array}$ \\
\hline $\begin{array}{l}\text { Dynamic } \\
\text { Mutation }\end{array}$ & $\begin{array}{l}\qquad x_{k}^{\prime}=x_{k} \times\left[1+(-1)^{t} \times\left(1-r^{\left(1-\frac{t}{T}\right)^{b}}\right)\right] \\
r \text { is a uniform random number on interval }(0,1), t \text { is } \\
\text { the current generation number, } T \text { is the maximum } \\
\text { number of generations, and } b=2 \text {. } \\
\text { Mutation probability is selected to be } 0.1 .\end{array}$ \\
\hline $\begin{array}{l}\text { Steady-State } \\
\text { Replacement }\end{array}$ & $\begin{array}{c}\text { Creating a number of offspring to replace the least } \\
\text { fit individuals. }\end{array}$ \\
\hline $\begin{array}{c}\text { Convergence } \\
\text { Criterion }\end{array}$ & $\begin{array}{l}\text { Iterations are continued until all generated } \\
\text { chromosomes become equal or } N^{\max }=1000\end{array}$ \\
\hline
\end{tabular}

Step 7B: Check all chromosomes if there is any chromosome with $F_{L}=1, F_{G}=1, F_{V}=1, F_{D}=1$ and $F_{F}>F_{\max }$, set $F_{\max }=F_{F}$, and then save it. Set $N_{i t}=N_{i t}+1$.

Step 8 (Convergence): If the maximum number of iterations is achieved, then print the solution and stop; otherwise, go to Step 3.

\section{Simulation Results}

Operations of the modified IEEE 14-bus [15, 32] and modified IEEE 30-bus test systems [33] without and with TCSC are studied to demonstrate the ability of the proposed GA method (Fig. 5). The imposed modifications are nonsmooth cost curves (Eq. (7)) for generators G1 and G7 (e.g., $e_{g}=50, f_{g}=0.063$ ), and for generators G2 and G8 (e.g., $e_{g}=40, f_{g}=0.098$ ). Five cases are studied (Table 2). The optimal location and size of a TCSC unit is estimated by maximizing the total social benefit function of Eq. (7). The minimum and maximum series capacitive compensation levels are limited to $0 \%$ and $70 \%$ of the compensated line reactance, respectively.

Both smooth (when $e_{g}=f_{g}=0$ in Eq. (5)) [15] and nonsmooth [18] generator cost curves are considered, and 
Table 2. Simulated cases of the IEEE 14-bus and IEEE 30bus systems

\begin{tabular}{|c|c|c|c|}
\hline \multirow{2}{*}{\begin{tabular}{|c|} 
Test System \\
IEEE 14- \\
Bus (Fig. 6) \\
\end{tabular}} & \multicolumn{2}{|r|}{ Simulated Cases } & \multirow{2}{*}{\begin{tabular}{|c|} 
Results \\
Tables $3-5,7,8$, \\
10, and Fig. 7 \\
\end{tabular}} \\
\hline & A & Base operation without/with TCSC & \\
\hline \multirow{4}{*}{$\mid \begin{array}{c}\text { IEEE 30- } \\
\text { Bus (Fig. 8) }\end{array}$} & $\mathrm{B}$ & Base operation without/with TCSC & Tables 5-10 \\
\hline & $\mathrm{C} 1$ & $\begin{array}{c}\text { Outage of line } 2-4 \\
\text { (between buses } 2 \text { nd } 4 \text { ) }\end{array}$ & \multirow{3}{*}{ Tables $5,7-10$} \\
\hline & $\mathrm{C} 2$ & Outage of unit 4 at bus 2 & \\
\hline & $\mathrm{C} 3$ & Increase of load 3 (by $150 \%$ ) at bus 4 & \\
\hline
\end{tabular}

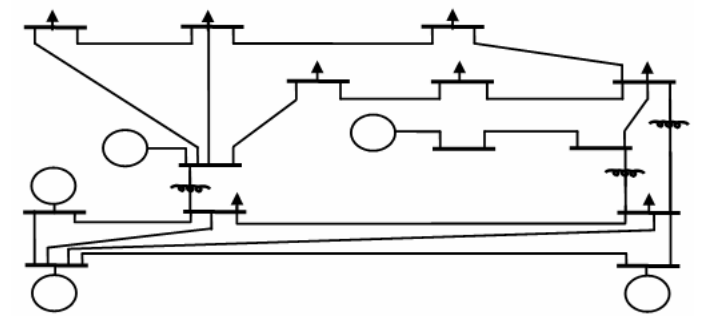

Fig. 6. The Modified IEEE 14-bus test system with nonsmooth cost curves (Eq. (7)) for G1 ( $\mathrm{e}_{\mathrm{g}}=50$, $\left.\mathrm{f}_{\mathrm{gi}}=0.063\right)$ and $\mathrm{G} 2\left(\mathrm{e}_{\mathrm{g}}=40, \mathrm{f}_{\mathrm{gi}}=0.098\right)$.

consumer benefit curves are assumed to be quadratic [17]. For the IEEE 30-bus, the second consumer benefit coefficient $\left(b_{d}\right)$ is multiplied by 5 to increase benefit function. Selected parameters are the number of generations $=1000$, number of populations $=73$, crossover rate $=0.9$, and mutation rate $=0.1$.

\section{Case A. Operation of IEEE 14-Bus System with TCSC}

This section presents the basic operation of the IEEE 14bus system (Fig. 6), and the process of optimally locating and sizing one TCSC unit with smooth/nonsmooth generators cost curves (Eq. (7)) and without/with transmission line flow constraints (Eq. (7)) to illustrate the ability of the proposed method. The objective function consists of 15 variables for 5 generation nodes (G5 only generates reactive power), 8 demand nodes, and 2 TCSC parameters. There are 20 possible locations to place one unit of TCSC. Simulation results (Tables 3-5, 7-8, 10, and Fig. 7) are analyzed as follows:

- Transmission line limits (Eq. (10)) overcome the congestion problem; however, social benefit decreases from $1972.3 \$ / \mathrm{h}$ to $1523.9 \$ / \mathrm{h}$ and from $1956.6 \$ / \mathrm{h}$ to $1529.67 \$ / \mathrm{h}$ for smooth and nonsmooth cost curves, respectively (Table 7 rows 1,6).

- Total generation and total load decreases from 381.9 and $357.7 \mathrm{MW} / \mathrm{h}$ to 336.9 and $327.64 \mathrm{MW} / \mathrm{h}$ for nonsmooth cost curves, respectively (Table 8 , row 1 ).

- Line flow constraints cause a significant decrease in social welfares, and they are the main causes of low social benefit and low loading levels. Some power consumers will have to bid higher prices in power markets because they cannot access cheaper power due to transmission limits.
To alleviate the overload, ISO will have to sacrifice cost to some extent. Therefore, ISO must encourage competition and reduce waste. FACTS devices can be used to direct power through uncongested transmission line(s) and provide cheaper power to be transferred from generators to consumers. Fig. 7 shows the individual welfare of each consumer without and with the line flow constraints using nonsmooth cost curves.

These simulation results also demonstrate the effect of one TCSC unit (including its optimal location and size) on social benefit. Note that benefits to individual consumers are not uniformly distributed and some participants may actually face reduction in their welfare/profit. However, TCSC will provide overall benefit to the system as a whole, whereas some market participants may benefit more from others. Further discussions are as follows:

- Transmission line limits (Eq. (8)) overcome the congestion problem; however, social benefit decreases from 1972.3 to $1523.9 \$ / \mathrm{h}$ and from 1956.6 to 1529.67 $\$ / \mathrm{h}$ for smooth and nonsmooth cost curves, respectively (Table 6 , rows 1,6 ).

- Total generation and total load decreases from 381.9 and $357.7 \mathrm{MW} / \mathrm{h}$ to 336.9 and $327.64 \mathrm{MW} / \mathrm{h}$ for nonsmooth cost curves, respectively (Table 6, row 1).

- Line flow constraints cause a significant decrease in social welfares, and they are the main causes of low social benefit and low loading levels. Some power consumers will have to bid higher prices in power markets because they cannot access cheaper power due to transmission limits.

- To alleviate the overload, ISO will have to sacrifice cost to some extent. Therefore, ISO must encourage competition and reduce waste. FACTS devices can be used to direct power through uncongested transmission line(s) and provide cheaper power to be transferred from generators to consumers. Fig. 6 shows the individual welfare of each consumer without and with the line flow constraints using nonsmooth cost curves.

These simulation results also demonstrate the effect of one TCSC unit (including its optimal location and size) on social benefit. Note that the benefits to individual consumers are not uniformly distributed and some participants may actually face reduction in their welfare/profit. However, TCSC will provide overall benefit to the system as a whole, whereas some market participants may benefit more from others. Further discussions are as follows:

- According to Table 6 (row 11), optimal sizing and placement of one TCSC will decrease generation cost, which will also improve social benefit from 1523.9 to $1604.57 \$ / \mathrm{h}$ and from 1529.6 to $1595.32 \$ / \mathrm{h}$ for smooth and nonsmooth cost curves, respectively.

- The main reason is the increase in load demands at nodes 11-13. Therefore, optimal placement/sizing of TCSC has been proven to be beneficial for the IEEE 14-bus system. 
- According to Table 3 (rows 11-14, columns 2 and 5), without any line flow constraints, there are very high load demands at nodes 11-14 (corresponding to loads 5-8) due to higher benefit coefficients (Eq. (5)). However, when line flow constraints are considered (Table 3, rows 11-14, columns 3 and 6), there is a substantial reduction in load demands and social benefit at theses nodes (Fig. 6).

- Line flow constraints will substantially increase loading levels (Table 3 ) at nodes 4-5 (corresponding to loads 1-2) and increase their social benefits (Fig. 6). The generation level of generator G4 (located at bus 6) is decreased and, therefore, the total system generation cost is increased (Table 3, row 4).

- After the placement of TCSC, load levels at nodes 4 and 5, which were previously elevated due to line flow constraints, are now decreased (Table 3, rows 5-6). This is due to their lower benefit coefficients compared with the other loads.

\section{Case B: Operation of IEEE 30-Bus System with TCSC}

Basic operation of the IEEE 30-bus system (Fig. 7) will be demonstrated before and after TCSC compensation. The objective function consists of 32 variables for 9 generation nodes, 21 demand nodes, and 2 TCSC parameters. There

Table 3. The optimal generation and load levels for IEEE 14-bus system with smooth and nonsmooth generation cost curve and with/without optimal locating/sizing of one TCSC device.

\begin{tabular}{c|c|c|c|c|c|c}
\hline \multirow{2}{*}{$\begin{array}{c}\text { Generator } \\
\text { or Load } \\
\text { (in MW) }\end{array}$} & \multicolumn{3}{|c|}{ Smooth generation cost curve } & \multicolumn{3}{|c}{$\begin{array}{c}\text { Nonsmooth generation cost } \\
\text { curve }\end{array}$} \\
\cline { 2 - 7 } & $\begin{array}{c}\text { Without } \\
\text { ine limits } \\
\text { \&ithout } \\
\text { TCSC }\end{array}$ & $\begin{array}{c}\text { With } \\
\text { line limits } \\
\text { \& } \\
\text { without } \\
\text { TCSC }\end{array}$ & $\begin{array}{c}\text { With } \\
\text { line } \\
\text { limits } \\
\text { \& with } \\
\text { TCSC }\end{array}$ & $\begin{array}{c}\text { Without } \\
\text { line limits } \\
\text { \& without } \\
\text { TCSC }\end{array}$ & $\begin{array}{c}\text { With line } \\
\text { limits } \\
\& \\
\text { without } \\
\text { TCSC }\end{array}$ & $\begin{array}{c}\text { With } \\
\text { line } \\
\text { limits } \\
\text { \& with } \\
\text { TCSC }\end{array}$ \\
\hline G1 & 94.22 & 97.25 & 88.84 & 90.07 & 90.64 & 88.84 \\
\hline G2 & 100 & 100 & 100 & 100 & 100 & 100 \\
\hline G3 & 100 & 100 & 100 & 100 & 100 & 100 \\
\hline G4 & 92.83 & 48.9 & 63.59 & 91.82 & 46.26 & 63.59 \\
\hline L1 & 58.10 & 116.90 & 107.7 & 55.15 & 121.01 & 107.7 \\
\hline L2 & 55.63 & 125.14 & 116.2 & 52.49 & 112.86 & 116.2 \\
\hline L3 & 5.63 & 8.02 & 5 & 5.02 & 5.94 & 5 \\
\hline L4 & 21.54 & 16.86 & 26.8 & 29.73 & 16.08 & 26.8 \\
\hline L5 & 35.79 & 22.15 & 15.4 & 26.32 & 23.97 & 15.4 \\
\hline L6 & 51.88 & 31.23 & 25.9 & 54.10 & 30.18 & 25.9 \\
\hline L7 & 71.90 & 7.16 & 9.2 & 71.49 & 6.68 & 9.2 \\
\hline L8 & 62.33 & 7.604 & 29.5 & 63.45 & 10.88 & 29.5 \\
\hline & & & & & & \\
\hline
\end{tabular}

Table 4. Optimal location and size of one unit TCSC in the modified IEEE 14-bus system with smooth and nonsmooth generation cost curves.

\begin{tabular}{c|c|c}
\hline & Smooth cost & Nonsmooth cost \\
\hline TCSC location & $6-13$ & $6-13$ \\
\hline Compensation rate (\%) & 25.445 & 25.305 \\
\hline Social welfare improvement & 80.650 & 65.650 \\
\hline
\end{tabular}

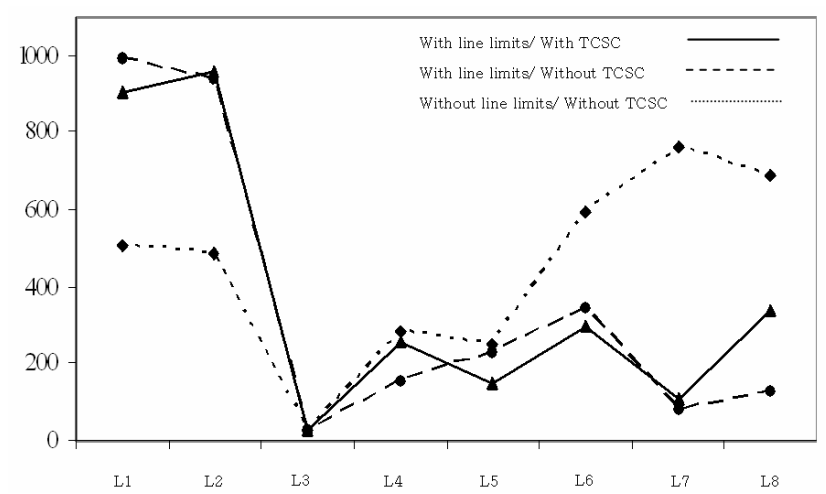

Fig. 6. Effect of line flow constraints and TCSC on the individual welfare of each market participant using nonsmooth generation cost curve.

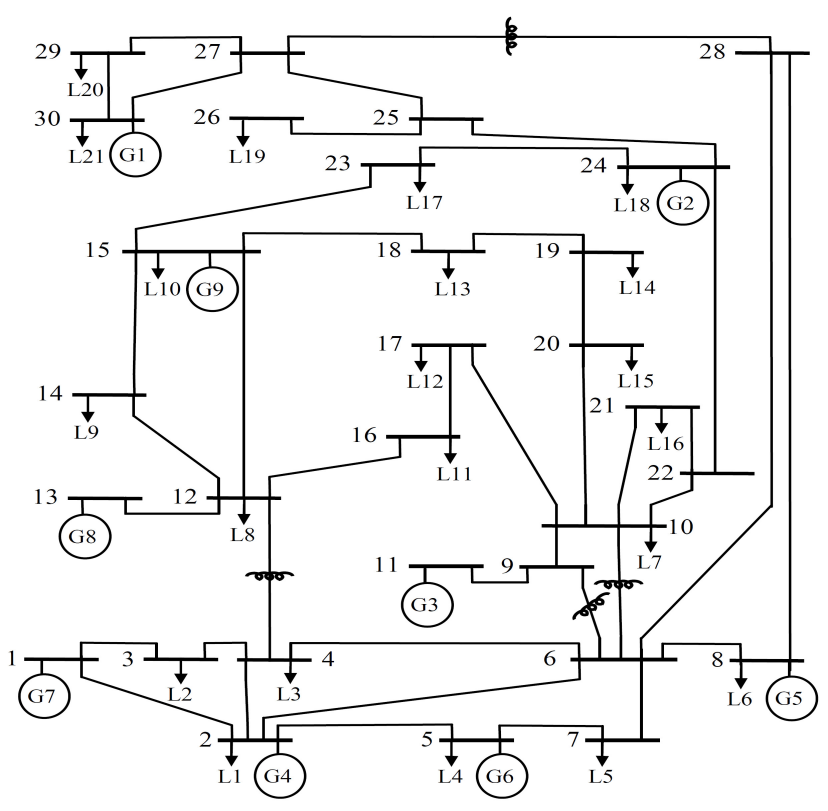

Fig. 7. Modified IEEE 30-bus test system; nonsmooth cost curves (Eq. (5)) for G1 and G7 $\left(e_{g}=50, f_{g}=0.063\right)$, and $\mathrm{G} 2$ and $\mathrm{G} 8\left(e_{g}=40, f_{g}=0.098\right)$.

are 41 possible locations to place one TCSC unit. Therefore, the optimization problem has become a problem that is too complex and large-scale for it to be solved with conventional approaches.

The proposed GA is applied and simulation results are presented in Tables 5-10. General comments are provided in the tables below.

With unconstrained conditions, congestion occurs in lines 1-2, 1-3, 2-4, and 3-4 (Table 5).

- According to Table 5, without line flow constraints, generators G1, G2, G3, and G8 are lightly loaded, whereas generators G5, G6, and G7 reach their maximum capacity. This is due to the different cost benefit coefficients (Eq. (5)), which are lower for G5, G6, and G7 and relatively higher for other generators. 
Table 5. The optimal generation and load levels in mw for ieee 30-bus system with smooth and nonsmooth generation cost curve and with/without optimal locating/sizing of one tcsc device for case b.

\begin{tabular}{c|c|c|c|c|c|c|c|c|c}
\hline & \multicolumn{4}{|c}{ Smooth generation cost curve } & \multicolumn{3}{c}{ Nonsmooth generation cost curve } \\
\cline { 2 - 11 } Generator & $\begin{array}{c}\text { Proposed method } \\
\text { fithout line } \\
\text { flow constraints } \\
\text { \&ithout } \\
\text { TCSC }\end{array}$ & $\begin{array}{c}\text { With line flow } \\
\text { constraints \& } \\
\text { without TCSC }\end{array}$ & $\begin{array}{c}\text { With line flow } \\
\text { constraints \& } \\
\text { with TCSC }\end{array}$ & $\begin{array}{c}\text { Without line } \\
\text { flow constraints } \\
\& \text { without } \\
\text { TCSC }\end{array}$ & $\begin{array}{c}\text { With line flow } \\
\text { constraints \& } \\
\text { without TCSC }\end{array}$ & $\begin{array}{c}\text { With line flow } \\
\text { constraints \& } \\
\text { with TCSC }\end{array}$ & $\begin{array}{c}\text { Without line } \\
\text { flow constraints } \\
\text { \& without } \\
\text { TCSC }\end{array}$ & $\begin{array}{c}\text { With line flow } \\
\text { constraints \& } \\
\text { without TCSC }\end{array}$ & $\begin{array}{c}\text { With line flow } \\
\text { constraints \& } \\
\text { with TCSC }\end{array}$ \\
\hline G1 & 10 & 10 & 10.14 & 10 & 10 & 10 & 10 & 10 & 10 \\
\hline G2 & 5 & 5 & 5.02 & 5 & 5 & 5 & 5 & 5 & 5 \\
\hline G3 & 5 & 5.01 & 5.04 & 5 & 5 & 5 & 5 & 5.06 & 5 \\
\hline G4 & 29.50 & 53.94 & 10 & 25.17 & 50.82 & 10 & 29.50 & 54.86 & 10 \\
\hline G5 & 50 & 46.83 & 47.38 & 50.00 & 50.00 & 50.00 & 50 & 48.67 & 42.26 \\
\hline G6 & 50 & 48.06 & 46.75 & 50.00 & 50.00 & 50.00 & 50 & 47.70 & 44.99 \\
\hline G7 & 100 & 58.23 & 92.07 & 100.00 & 59.98 & 83.71 & 100 & 57.87 & 97.88 \\
\hline G8 & 10 & 21.44 & 36.13 & 10 & 10 & 17.14 & 10 & 27.87 & 38.91 \\
\hline G9 & 27.80 & 37.73 & 35.65 & 31.57 & 45.18 & 55.57 & 27.80 & 29.17 & 35.40 \\
\hline
\end{tabular}

Table 6. Cost-benefit analysis by the comparison of results generated by the proposed ga and sqp for the ieee 30 bus test systems with smooth and nonsmooth cost curves.

\begin{tabular}{|c|c|c|c|c|c|c|c|c|c|c|}
\hline \multirow[b]{3}{*}{ Case } & & \multicolumn{6}{|c|}{ Smooth generation cost curve } & \multirow{2}{*}{\multicolumn{3}{|c|}{$\begin{array}{c}\text { Nonsmooth generation cost curve } \\
\text { Proposed method }\end{array}$}} \\
\hline & & \multicolumn{3}{|c|}{ Proposed method } & \multicolumn{3}{|c|}{ SQP [16] } & & & \\
\hline & & $\begin{array}{c}\text { Social } \\
\text { Benefit }(\$ / h)\end{array}$ & $\begin{array}{l}\text { Generation } \\
\text { Cost }(\$ / h)\end{array}$ & $\begin{array}{c}\text { Customer } \\
\text { Benefit } \\
(\$ / \mathrm{h})\end{array}$ & $\begin{array}{c}\text { Social } \\
\text { Benefit } \\
(\$ / \mathrm{h}) \\
\end{array}$ & $\begin{array}{l}\text { Generation } \\
\text { Cost }(\$ / h)\end{array}$ & $\begin{array}{l}\text { Customer } \\
\text { Benefit }(\$ / \mathrm{h})\end{array}$ & $\mid \begin{array}{c}\text { Social } \\
\text { Benefit }(\$ / \mathrm{h})\end{array}$ & $\begin{array}{l}\text { Generation } \\
\text { Cost }(\$ / h)\end{array}$ & $\begin{array}{c}\text { Customer } \\
\text { Benefit }(\$ / \mathrm{h})\end{array}$ \\
\hline \multirow{5}{*}{$\begin{array}{l}\text { Without line flow } \\
\text { constraints } \\
\& \text { without TCSC }\end{array}$} & A & 1972.36 & 1665.13 & 3637.50 & 1942.64 & 1694.86 & 3637.50 & 1956.66 & 1646.15 & 3602.81 \\
\hline & B & 8106.311 & 6109.912 & 14225.03 & 8127.360 & 6097.670 & 14225.03 & 8083.674 & 6134.477 & 14225.03 \\
\hline & $\mathrm{C} 1$ & 8101.320 & 6123.710 & 14225.03 & 8117.150 & 6107.880 & 14225.03 & 8094.399 & 6130.631 & 14225.03 \\
\hline & $\mathrm{C} 2$ & 8273.252 & 5951.779 & 14225.03 & 8329.860 & 5895.170 & 14225.03 & 8268.365 & 5956.666 & 14225.03 \\
\hline & $\mathrm{C} 3$ & 8434.290 & 6770.468 & 15204.76 & 8459.020 & 6745.74 & 15204.76 & 8429.859 & 6774.901 & 15204.76 \\
\hline \multirow{5}{*}{$\begin{array}{l}\text { With line flow constraints } \\
\& \text { without TCSC }\end{array}$} & $\mathrm{A}$ & 1523.92 & 1407.15 & & 1502.6 & 1428.47 & & & 1369.59 & 2899.26 \\
\hline & $\mathrm{B}$ & 7870.95 & 6354.08 & & 7854.920 & 6370.110 & & & & 25.03 \\
\hline & $\mathrm{C} 1$ & 7768.00 & 6449.47 & 1422 & 7763.300 & 6461.730 & & 7753.77 & & 5.03 \\
\hline & $\mathrm{C} 2$ & 7154.83 & 6976.92 & 14225.03 & 7128.870 & 7096.16 & 14225.03 & 7147.25 & 6984.60 & 14225.03 \\
\hline & $\mathrm{C} 3$ & 8077.65 & 7114.29 & 15204.76 & 8027.860 & 7176.90 & 15204.76 & 8052.61 & 7152.14 & 15204.76 \\
\hline \multirow{5}{*}{$\begin{array}{c}\text { With line flow constraints } \\
\& \text { with TCSC }\end{array}$} & $\mathrm{A}$ & 1604.57 & 1436.26 & 3040.83 & 1604.57 & 1436.26 & 3040.83 & 1595.32 & 1445.51 & 3040.83 \\
\hline & $\mathrm{B}$ & 7991.08 & 6233.94 & 14225.03 & 8000.500 & 6224.530 & 14225.03 & 7956.55 & 6268.47 & 14225.03 \\
\hline & $\mathrm{C} 1$ & 7901.07 & 6323.95 & 14225.03 & 7864.410 & 6360.620 & 14225.03 & 7878.03 & 6347.00 & 14225.03 \\
\hline & $\mathrm{C} 2$ & 8227.21 & 5977.90 & 14225.03 & 8242.800 & 5982.230 & 14225.03 & 8201.16 & 6023.86 & 14225.03 \\
\hline & $\mathrm{C} 3$ & 8330.33 & 6874.42 & 15204.76 & 8323.390 & 6881.370 & 15204.76 & 8323.77 & 6880.98 & 15204.76 \\
\hline
\end{tabular}

- With line constraints, the generation level of G7 is substantially decreased to about $60 \mathrm{MW}$. This is the maximum capacity of lines connected to this generator at node 1 . In contrast to G7, loading levels of G4, G8 and G9 are significantly increased to fulfill load requirements. As a result, overall social benefit is decreased (Table 6).

- After the optimal placement and sizing of TCSC, a considerable increase in generation of G7 (to transfer more power from node 1 to node 2) reduces generation cost and increases social benefit (Table 6). These results demonstrate the ability of TCSC in improving system operation with line flow constraints.

- After TCSC compensation, social benefit increases and total generation cost decreases for both smooth and nonsmooth cost curves. This demonstrates the effectiveness of the optimal sizing and placement of TCSC.

\section{Case C. Operation of IEEE 30-Bus System with Congestion}

Three additional cases (Table 2, rows 4-6) are presented to further illustrate the ability of the proposed method and the effect of TCSC in overcoming congestion. Congested lines (without line constraints) are listed in Table 8.

Table 9 shows social welfare improvement by locating and sizing the TCSC. According to Table 7, the inclusion of TCSC does not considerably improve generation level and customer benefit for all cases.

This indicates that the systems under consideration have the capability of supporting maximum load under assumed congestion conditions.

- Simulations are performed (Tables 5-10) by assuming outages of line $2-4$, outage of unit 6 , and a substantial increase in load 3.

- According to Table 6 (row 5, column 11), social welfare is improved to $7878.03 \$ / \mathrm{h}$ after optimal 
Table 7. System analysis results for ieee 30 bus test systems with smooth cost curves (POWERS ARE IN MW)

\begin{tabular}{|c|c|c|c|c|c|c|c|c|c|c|c|c|}
\hline \multicolumn{9}{|c|}{ Smooth generation cost curve } & \multicolumn{4}{|c|}{ Nonsmooth generation cost curve } \\
\hline \multirow{3}{*}{ Case } & \multicolumn{4}{|c|}{ Operation without TCSC } & \multicolumn{4}{|c|}{ Operation with TCSC } & \multirow{2}{*}{\multicolumn{2}{|c|}{$\begin{array}{c}\text { Operation without TCSC } \\
\text { Proposed method } \\
\end{array}$}} & \multirow{2}{*}{\multicolumn{2}{|c|}{$\begin{array}{c}\text { Operation with TCSC } \\
\text { Proposed method } \\
\end{array}$}} \\
\hline & \multicolumn{2}{|c|}{ Proposed method } & \multicolumn{2}{|l|}{ SQP [16] } & \multicolumn{2}{|c|}{ Proposed method } & \multicolumn{2}{|c|}{ SQP [16] } & & & & \\
\hline & Total generation & $\begin{array}{l}\text { Total } \\
\text { load }\end{array}$ & Total generation & $\begin{array}{l}\text { Total } \\
\text { load }\end{array}$ & $\begin{array}{c}\text { Total } \\
\text { generation }\end{array}$ & \begin{tabular}{|l|} 
Total \\
load \\
\end{tabular} & $\begin{array}{c}\text { Total } \\
\text { generation }\end{array}$ & $\begin{array}{l}\text { Total } \\
\text { Load }\end{array}$ & $\begin{array}{c}\text { Total } \\
\text { generation }\end{array}$ & $\begin{array}{l}\text { Total } \\
\text { load }\end{array}$ & Total generation & $\begin{array}{l}\text { Total } \\
\text { load }\end{array}$ \\
\hline A & 346.22 & 335.08 & 361.13 & 347.41 & 352.44 & 335.70 & 366.11 & 352.44 & 336.90 & 327.64 & 351.86 & $335.7 x$ \\
\hline $\mathrm{B}$ & 286.27 & 283.40 & 285.98 & 283.40 & 288.46 & 283.40 & 286.42 & 283.40 & 286.23 & 283.40 & 289.46 & 283.41 \\
\hline $\mathrm{C} 1$ & 286.23 & 283.40 & 286.73 & 283.40 & 289.24 & 283.40 & 286.78 & 283.40 & 286.16 & 283.40 & 289.03 & $\overline{283.4 c}$ \\
\hline $\mathrm{C} 2$ & 285.31 & 283.40 & 286.23 & 283.40 & 290.27 & 283.40 & 286.47 & 283.40 & 285.31 & 283.4 & 289.30 & 283.40 \\
\hline $\mathrm{C} 3$ & 320.63 & 317.20 & 321.07 & 317.20 & 323.55 & 317.20 & 321.07 & 317.20 & 320.57 & 317.2 & 323.27 & 317.2( \\
\hline
\end{tabular}

Table 8. Congested lines of the simulated cases based on Table 2 without line flow constraints and without tcsc.

\begin{tabular}{c|c|c}
\hline Case & Smooth generation cost & Nonsmooth generation cost \\
\hline A & $4-6,6-11,6-12,6-13,5-7$, & $4-6,6-12,6-13,5-7,5-9$, \\
\hline B & $1-2,1-3,2-4,3-4$ & $1-2,1-3,2-4,3-4$ \\
\hline C1 & $1-2,1-3,2-4,3-4$ & $1-2,1-3,2-4,3-4$ \\
\hline C2 & $1-2,1-3,3-4$ & $1-2,1-3,3-4$ \\
\hline C3 & $1-2,1-3,2-4,3-4,2-6$ & $1-2,1-3,2-4,3-4,2-6$ \\
\hline
\end{tabular}

Table 9. Near-optimal location and size of one tcsc unit in the ieee 30-bus system with smooth/nonsmooth generation cost curves.

\begin{tabular}{|c|c|c|c|}
\hline \multicolumn{2}{|r|}{ Case } & $\begin{array}{l}\text { Smooth cost } \\
\text { curve }\end{array}$ & $\begin{array}{l}\text { Nonsmooth cost } \\
\text { curve }\end{array}$ \\
\hline \multirow{3}{*}{ B } & TCSC location & Line 1-2 & Line $1-2$ \\
\hline & Compensation rate $(\%)$ & 58.74 & 66.97 \\
\hline & $\begin{array}{l}\text { Improvement in social welfare } \\
(\$ / \mathrm{h})\end{array}$ & 187.41 & 161.65 \\
\hline \multirow{3}{*}{$\mathrm{C} 1$} & TCSC location & Line 1-2 & Line $1-2$ \\
\hline & Compensation rate $(\%)$ & 55.87 & 56.61 \\
\hline & $\begin{array}{l}\text { Improvement in social welfare } \\
(\$ / \mathrm{h})\end{array}$ & 133.07 & 124.26 \\
\hline \multirow{3}{*}{$\mathrm{C} 2$} & TCSC location & Line $1-2$ & Line $1-2$ \\
\hline & Compensation rate $(\%)$ & 61.17 & 61.02 \\
\hline & $\begin{array}{l}\text { Improvement in social welfare } \\
(\$ / \mathrm{h})\end{array}$ & 1072.40 & 1053.90 \\
\hline \multirow{3}{*}{ C3 } & TCSC location & Line $1-2$ & Line $1-2$ \\
\hline & Compensation rate $(\%)$ & 45.22 & 44.67 \\
\hline & $\begin{array}{l}\text { Improvement in social welfare } \\
(\$ / \mathrm{h})\end{array}$ & 252.68 & 271.16 \\
\hline
\end{tabular}

Table 10. Required number of iterations $\left(n_{i t}\right)$ for optimally locating and sizing one tcsc device using the proposed ga for the five cases of Table 3 .

\begin{tabular}{c|c|c}
\hline Case & Smooth cost curve & Nonsmooth cost curve \\
\hline A & 609 & 619 \\
\hline B & 682 & 729 \\
\hline C1 & 703 & 745 \\
\hline C2 & 725 & 732 \\
\hline C3 & 691 & 751 \\
\hline
\end{tabular}

rescheduling. This is done by the optimal placement of one TCSC at line 1-2 with a composition level of $56.6 \%$ (Table 9, row 5, last column).

- In Case C1, line 2-4 is not available because of the physical limitations on lines $1-2$ and $1-3$. Generator
G7 (at bus 1) will not be operating at an optimal point. Therefore, ISO needs to reschedule other generators.

- In Case $\mathrm{C1}$, line 2-4 is not available because of the physical limitations on lines 1-2 and 1-3. Generator G7 (at bus 1) will not be operating at an optimal point. Therefore, ISO needs to reschedule other generators. According to Table 6 (row 5, column 11), social welfare is improved to $7878.03 \$ / \mathrm{h}$ after optimal rescheduling. This is done by the optimal placement of one TCSC at line 1-2 with a composition level of $56.6 \%$ (Table 9; row 5, last column).

- Note that TCSC improves social benefits in all cases (Table 6, columns 2, 5, 8, 11) with nonsmooth/smooth generation curves. Therefore, optimal sizing and placement of TCSC is also justified and recommended for these cases.

- According to Table 6, the effect of sine components is to increase generation cost. Therefore, ISO needs to consider the actual valve setting points in the objective function by including nonsmooth characteristics to get more accurate results and perform realistic cost.

- Note that all line loadings are at their near maximum levels due to their high cost benefit coefficients (Eq. (5)), as well as system ability in fulfilling load demands.

- Transmission line limits (Eq. (8)) overcome the congestion problem; however, social benefit decreases from 8106.31 to $7870.95 \mathrm{~S} / \mathrm{h}$ and from 8083.674 to $7794.9 \$ / \mathrm{h}$ for smooth and nonsmooth cost curves, respectively (Table 6 , row 7 ). Therefore, as with the IEEE 14-bus system, line flow constraints are the main causes of low social benefit and low loading levels.

- Therefore, investigating the effect of generator curves is easy. According to Table 6, the inclusion of sin component on the generator's characteristics increases total generation cost from 6354.08 to $6430.1 \$ / \mathrm{h}$ and decreases social benefit from 7870.95 to $7794.9 \$ / \mathrm{h}$, respectively.

- In the Modified IEEE 30-bus test system, all loads are nearly at their maximum levels due to their high cost benefit coefficients, as well as their system ability in fulfilling load demands. Therefore, investigating the effect of generator curves is easy.

- According to Table 6, the inclusion of the sine 
component on the generator's characteristics increases total generation cost and decreases total system social welfare.

- Considering the valve point loading effect in objective function changes the size and investment cost of the TCSC and affects the amount of social welfare. Therefore, ISO needs to consider actual valve setting points in the objective function by including nonsmooth characteristics to get results that are more accurate and perform realistic cost (Table 6).

- The required number of iterations for optimally locating and sizing one TCSC device for five simulated cases (Table 2) are presented in Table 10. The table shows that considering valve point increases the required iteration.

\section{Conclusions}

A real code-based GA is proposed and implemented to perform congestion management and maximize social benefit by optimally locating (and sizing) one TCSC unit, and by the optimal rescheduling of generation and demand levels.

- A suitable formulation of TCSC is presented and included in the objective function.

- Using real code-based in GA guarantees fast convergence to the best solution for smooth and nonsmooth generator cost curves. Based on the simulation results for IEEE 14-bus and 30-bus systems, the following conclusions are obtained:

- TCSC has the ability to redistribute power flow, influence loads and generations levels at different buses, and significantly increase social benefit (Tables 3-9). Installation of TCSC offers benefits that far exceed its cost for the system conditions studied (Table 9).

- TCSC has different effects on the welfare of individual participants and may affect double-sided auction price of each bus differently. Therefore, some participants may benefit more than the others (Table 6).

The benefits of using TCSC may not be considerable at low levels of demand and generation. Simulation studies over an extended period of time would be required to evaluate the overall benefit of TCSC for an actual system.

\section{References}

[1] D. Shirmohammadi, B. Wollenberg, A. Vojdani, P. Sandrin, M. Pereira, F. Rahimi, T. Schneider and B. Stott, "Transmission dispatch and congestion management in the emerging energy market structures", IEEE Trans. Power Syst., vol. 13, Issue 4, pp. 14661474, Nov. 1998.

[2] J. Hazra and A.K. Sinha, "Congestion management using multi objective particle swarm optimization", IEEE Trans. Power Syst., vol. 22, Issue 4, pp. 17261734, Nov. 2007.

[3] S.M.H. Nabavi, S. Jadid, M.A.S. Masoum and A. Kazemi, "Congestion management in nodal pricing with genetic algorithm", International Conference on Power Electronics, Drives and Energy Syst., PEDES '06, pp. 1-5, 12-15 Dec. 2006.

[4] C.Z. Karatekin and C. Uçak, "Sensitivity analysis based on transmission line susceptances for congestion management", Electric Power Systems Research, vol. 78, Issue 9, pp. 1485-1493, Sept. 2008

[5] D. Gautam, N. Mithulananthan, "Locating Distributed Generator in the LMP-based Electricity Market for Social Welfare Maximization", Electric Power Components and Systems, 35 (5), pp. 489-503 (2007).

[6] J. D. Weber and T. J. Overbye, "An individual welfare maximization algorithm for electricity markets", IEEE Trans. Power Syst., 17(3), pp 590 596 (2002).

[7] L, Hongrui, S. Yanfang, Z.B. Zabinsky, L. ChenChing, A. Courts, and J. Sung-Kwan, "Social welfare maximization in transmission enhancement considering network congestion", IEEE Trans. Power Syst, 23(3), pp 1105-1114 (2008).

[8] P. A. J. Fonseka and G. B. Shrestha, "Network expansion under frameworks of regulated monopoly and merchant transmission," IEEE Singapore Power Tech. Conf., 2, pp. 1716-1721 (2004).

[9] M. O. Buygi, G. Balzer, H. M. Shanechi, and M. Shahidehpour, "Market-based transmission expansion planning," IEEE Trans. Power Syst., 19 (4), pp. 2060-2067 (2004).

[10] S. Gerbex, R. Cherkaoui and A.J. Germond, "Optimal location of multitype FACTS devices in a power system by means of genetic algorithms", IEEE Trans. Power Syst., vol. 16, pp. 537-544, 2001.

[11] S.N. Singh and A.K. David, "Optimal location of FACTS devices for congestion management", Electric Power Systems Research, vol. 58, Issue 2, pp. 71-79, 21 June 2001.

[12] S. Bruno and M. LaScala, "Unified power flow controllers for security constrained transmission management", IEEE Trans. Power Syst., pp. 418-426, 18 February 2004.

[13] K.S. Verma, S.N. Singh and H.O. Gupta, "Location of unified power flow controller for congestion management", Electric Power Systems Research, vol. 58, Issue 2, pp. 89-96, 21 June 2001.

[14] J. Zhang and A. Yokoyama, "Optimal power flow control for congestion management by interline power flow controller (IPFC)", International Conference on Power System Technology, PowerCon, pp.1-6, Oct. 2006.

[15] G.B. Shrestha and W. Feng, "Effects of series 
compensation on spot price power markets", Electric Power Systems Research, vol. 27, pp. 428-436, 2005.

[16] Kankar Bhattacharya, Math H. J. Bollen, Jaap E. Daalder, "Operation of restructured power systems" Springer, 2001

[17] K. Singh, N.P. Padhy, and J.D. Sharma, "Social welfare maximization considering reactive power and congestion management in the deregulated environment", Electric Power Components and System, 38(1), pp 50-71(2010).

[18] S. Sayah and Kh. Zehar, "Modified differential evolution algorithm for optimal power flow with nonsmooth cost functions", Electric Power Systems Research, vol. 49, pp. 3036-3042, 2008.

[19] X. P. Wang and L. P. Cao, "Genetic algorithms theory, application and software realization", Xi'an Jiaotong University, Xi'an, China, 1998.

[20] Y. L. Abdel-Magid, M. A. Abido, S. Al-Baiyat, and A. H. Mantawy, "Simultaneous stabilization of multimachine power systems via genetic algorithms," IEEE Trans. Power Syst., vol. 14, pp. 1428-1439, Nov. 1999.

[21] Daneshfar, F., Bevrani, H., "Load-frequency control: a GA-based multi-agent reinforcement learning", Generation, Transmission \& Distribution, IET,Vol: 4, Issue: 1, 2010, pp. 13-26

[22] Furong Li, Pilgrim, J.D., Dabeedin, C., Chebbo, A., Aggarwal, R.K., "Genetic algorithms for optimal reactive power compensation on the national grid system", IEEE Trans. Power Syst.,Vol. 20, 2005, pp. 493-500

[23] A. Ulinuha, M.A.S. Masoum and S.M. Islam, "Optimal Scheduling of LTC and Shunt Capacitors in Large Distorted Distribution Systems using Genetic Algorithms", IEEE Trans. on Power Delivery, Vol.23, No.1, pp.434-441, Jan 2008.

[24] Senjyu, T., Saber, A.Y., Miyagi, T., Shimabukuro, K., Urasaki, N., Funabashi, T., "Fast technique for unit commitment by genetic algorithm based on unit clustering”, IEEE Trans. Power Syst., Vol. 152, 2005, pp. 705-713.

[25] Bhattacharya, A., Chattopadhyay, P.K., "Biogeography-Based Optimization for Different Economic Load Dispatch Problems", IEEE Trans. Power Syst., Vol. 25, 2010, pp. 1064-1077.

[26] Todorovski, M., Rajicic, D., “An initialization procedure in solving optimal power flow by genetic algorithm", IEEE Trans. Power Syst.,Vol. 21, 2006, pp. $480-487$.

[27] Kannan, S., Baskar, S., McCalley, J.D., Murugan, P., "Application of NSGA-II Algorithm to Generation Expansion Planning", IEEE Trans. Power Syst., Vol. 24, 2009, pp. 454-461.

[28] Granelli, G., Montagna, M., Zanellini, F.; Bresesti, P.; Vailati, R.; "A genetic algorithm-based procedure to optimize system topology against parallel flows",
IEEE Trans. Power Syst., Vol. 21, 2006, pp. 333 340.

[29] Ying-Yi Hong Saw-Yu Ho, "Genetic algorithm based network reconfiguration for loss minimization in distribution systems", Power Engineering Society General Meeting, 2003, IEEE.

[30] E. Haesen, M. Espinoza, B. Pluymers, I. Goethals, T. Vu Van, J.Driesen, R. Belmans, B. De Moor, "Optimal Placement and Sizing of Distributed Generator Units Using Genetic Optimization Algorithms," Electrical Power Quality and Utilisation Journal, Vol. XI, Nr. 1, pp. 97- 104, 2005

[31] Samaan, N., Singh, C., " Adequacy Assessment of Power System Generation Using A Modified Simple Genetic Algorithm", IEEE Trans. Power Syst., Vol. 17, 2002, pp. 974-981.

[32] R.S. Fang and A.K. David, "Optimal dispatch under transmission contracts," IEEE Trans. Power Syst., vol. 14, no. 2, pp. 732-737, May 1999.

[33] M, Shiddehpour, H. Yamin and Z.Y. LI, "Market Operations in Electric Power System", New York: Wiley, pp. 477-478, 2002

[34] R. D. Zimmerman, C. E. Murillo-Sanchez, and D. Gan, MATPOWER: A Matlab Power System Simulation Package 2006.

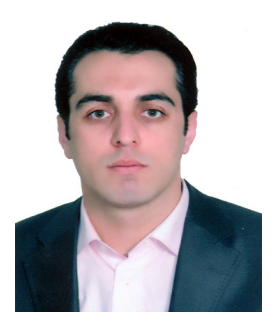

Syed M.H Nabavi (S'09-M'11) received his B.S. (Honor Student) degree in Electrical and Computer Engineering from Islamic Azad University, Bushehr Brach, Bushehr, Iran in 2001, and M.S. (Honor Student) and Ph.D degrees in Electrical and Computer Engineering in 2004 and 2011, respectively, from the Iran University of Science and Technology, Tehran, Iran. His research interests include optimization, power system operation, and control. Currently, he is an Assistant Professor at Islamic Azad University, Tabriz Brach, Iran.. He is a member of IEEE.

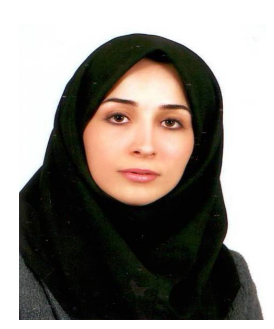

Somayeh. Hajforoosh received her B.S. and M.S. degrees in Electrical and Computer Engineering from Ferdowsi University, Mashhad, Iran and Islamic Azad University, South Tehran Brach, Tehran, Iran, in 2005 and 2010, respectively. Her research interests include nonlinear and adaptive control, power system modeling, control and optimization.

Sajad. Hajforoosh received his B.S. degree in Electrical and Computer Engineering in 2010. His research interests include optimization, and programming. Currently, he is a master student at Iran University of Science \& Technology, Tehran, Iran. 
Ali. Karimi received his B.S. and M.S. degrees in Electrical and Computer Engineering in 2001 and 2006, respectively, from Iran University of Science \& Technology, Tehran, Iran. Currently, he is a PHD student at Iran University of Science \& Technology, Tehran, Iran.

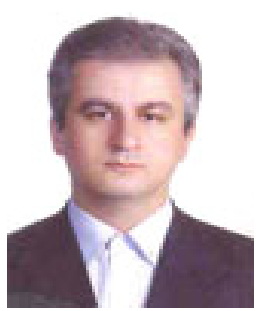

Kamran Khafafi received his B.S. and

M.S. degrees in Electrical and

Computer Engineering in 1991 and 1996, respectively, from Tabriz University, Tabriz, Iran. Currently, he is a faculty member at Islamic Azad University, Tabriz branch, Tabriz, Iran. 